\title{
Who has a Choice?: Survey-Based Predictors of Volitionality in Facebook Use and Non-use
}

\author{
PATRICK SKEBA, Lehigh University, USA \\ DEVANSH SAXENA, Marquette University, USA \\ SHION GUHA, University of Toronto, Canada \\ ERIC P. S. BAUMER, Lehigh University, USA
}

This paper examines volitionality of Facebook usage, that is, which individuals feel they have a choice about whether or not to use the site. It analyzes data from two large surveys, conducted three years apart. Across the two surveys, a variety of factors impacted whether or not respondents saw their Facebook usage as a matter of their own choice, such as engaging in non-use behaviors, measures of Facebook addiction, a sense of their own agency, and, across both studies, level of education. These results expand on prior literature around technology use and non-use, especially in terms of which populations may feel obligated to use, or be unwillingly prevented from using, social media such as Facebook. Furthermore, they provide potential implications both for future work and for technology policy.

CCS Concepts: • Human-centered computing $\rightarrow$ Empirical studies in HCI; HCI theory, concepts and models; $\bullet$ Social and professional topics $\rightarrow$ User characteristics.

Additional Key Words and Phrases: volitionality, non/use, surveys, modeling

ACM Reference Format:

Patrick Skeba, Devansh Saxena, Shion Guha, and Eric P. S. Baumer. 2021. Who has a Choice?: Survey-Based Predictors of Volitionality in Facebook Use and Non-use. Proc. ACM Hum.-Comput. Interact. 5, GROUP, Article 223 (July 2021), 25 pages. https://doi.org/10.1145/3463935

\section{INTRODUCTION}

Who has a choice about whether or not they use social media? Of the 2.7 billion people who used Facebook each month in 2020, which people did so out of a sense of obligation or necessity, rather than their own personal satisfaction [18]? Prior research finds that people use Facebook not only for the networking, entertainment, and other affordances of the platform, but also out of fear that they will miss out on important social opportunities or cause strain on relationships, among other reasons $[5,29,76]$. Volitionality, or one's feeling of agency and freewill in decision-making, is an important, but often overlooked component of users' experiences with Facebook and other social media platforms. A growing body of work describes a number of potential harms associated with Facebook use, including the spread of misinformation [22], cyberbullying [51], and psychological stress [84], which could affect those who feel that they do not have a choice to leave. Given that

Authors' addresses: Patrick Skeba, Lehigh University, 322 Building C, 113 Research Drive, Bethlehem, PA, 18015, USA, pts217@lehigh.edu; Devansh Saxena, Marquette University, Cudahy Hall, 1313 W Wisconsin Avenue, Milwaukee, WI, 53233, USA, devansh.saxena@marquette.edu; Shion Guha, University of Toronto, 140 St. George Street, Toronto, Ontario, Canada shion.guha@utoronto.ca; Eric P. S. Baumer, Lehigh University, 235 Building C, 113 Research Drive, Bethlehem, PA, 18015 USA, ericpsb@lehigh.edu.

Permission to make digital or hard copies of all or part of this work for personal or classroom use is granted without fee provided that copies are not made or distributed for profit or commercial advantage and that copies bear this notice and the full citation on the first page. Copyrights for components of this work owned by others than ACM must be honored. Abstracting with credit is permitted. To copy otherwise, or republish, to post on servers or to redistribute to lists, requires prior specific permission and/or a fee. Request permissions from permissions@acm.org.

(C) 2021 Association for Computing Machinery.

2573-0142/2021/7-ART223 \$15.00

https://doi.org/10.1145/3463935

Proc. ACM Hum.-Comput. Interact., Vol. 5, No. GROUP, Article 223. Publication date: July 2021. 
some number of Facebook users can be described as non-volitional, how should social media researchers, designers, and policy makers consider decisions which could impact millions of people who are unwillingly engaged with the system?

Evidence from a variety of sources suggests that many individuals do not have control over their own social media usage. Some work argues that social media, such as Facebook, should be seen as potentially addictive $[2,37,43]$, though others question the utility or validity of this notion for understanding people's use of a communication technology [20,65]. Other work notes the automatic or compulsive nature with which some people use social technologies, as well as the lengths to which they go to curtail that use $[56,64,75]$. Prior work has also highlighted systematic barriers that can prevent those who want to use social media from doing so [70, 81-83]. For Facebook in particular, a variety of high-profile events have highlighted mixed feelings about the site among many $[53,69,74]$. Some work has focused on such individuals who feel conflicted, either because they want to stop using social media but feel that they cannot, or because they leave and then find themselves subsequently returning without intending to do so [4, 7, 9, 40,71]. Thus, the question of volitionality pervades much prior work on social technology use and non-use.

However, relatively little work has directly investigated the question of who believes that they have a choice about whether or not to use social media. This conception of volitionality bears some resemblance to the phenomenon of sense of agency, or "whether we can reflectively explain our action in terms of our beliefs, desires, and intentions" [31, p. 18]. Although "there is no consensus about how to define the sense of agency" [30, p. 1], prior work applying the concept to social media [9] suggests three main aspects: awareness of one's own actions, intentionality in those actions, and a capacity for action. The study of volitionality in technology non-use relates to this intentionality aspect, i.e., whether an individual intentionally chose to use, or to forgo use of, a given technology. Work on exclusion or disenfranchisement [41,70, 81-83] suggests that demographic and/or socioeconomic factors may play a role in predicting nonvolitional technology non-use. Other studies highlight the influence of both individual attributes and social tensions that either draw people to Facebook or keep them off the site against, potentially their will [5, 7, 9, 40, 77].

Such questions around volitionality lie at the heart of how we conceptualize the use and adoption of most social technologies. Foundational work has demonstrated various interpersonal forces that play a significant role in whether certain technologies are adopted or not [38, 39, 59]. Significant efforts have also been devoted to overcoming infrastructural, geopolitical, and other barriers that hinder some people from using communication and information technologies [e.g., 21]. However, researchers rarely study, designers rarely build, and governments rarely regulate in terms of those who feel compelled to use a technology, even though they might prefer not to.

This paper presents results from the analysis of two large scale surveys related to volitionality of Facebook use. We chose to focus on Facebook, as it is the single most commonly used social media site [62] (for more on this point, see Baumer et al. [5]). For both data sets, we use binary logistic regression to construct a model for determining which factors predict whether or not a respondent reports that they have a choice about their own Facebook usage. The results show that volitionality is predicted by such factors as personality [19, 32], level of education, experiences resembling addiction [2], and others.

Thus, this paper offers a three-part contribution. First, we demonstrate that a small but nonnegligible proportion of respondents report that they have no choice about their own Facebook non/use ${ }^{1}$. Second, we identify statistical regularities among those respondents, contributing an understanding of who does, and who does not, report having a choice about whether or not to use

${ }^{1}$ We employ the term "non/use" as a shorthand for "use and non-use" [6]. 
Facebook. Finally, we conclude by considering potential implications of these results, both in terms of technology design and in terms of technology policy.

\section{RELATED WORK}

\subsection{Volitionality and Technology Non/use}

Volitionality has long played a role in the conceptualization of technology non-use. In her foundational work, Wyatt [81] proposes two key dimensions of non-use: temporality and volitionality. For any given technology, these combine to form a four-part typology: resistors, who have never adopted the technology; rejecters, who previously used the technology but willingly gave it up; the excluded, who have been prevented from using the technology; and the expelled, who previously used the technology but were stopped from doing so against their will. Satchell and Dourish [70] also suggest several different types of non-use, some of which vary in terms of volitionality. On the one end, "active resistance [includes] those who steadfastly refuse to adopt a technology, in active and considered ways" [70, p. 11]. At the other end, disenfranchisement refers to those individuals who are prevented from using a technology, due either to "physical and cognitive impairments" or to "economic, social, infrastructural, geographic, and other [constraints]" [70, p. 12]. As recently as 2014, Wyatt was quoted as declaring that "there is still a digital divide, people!" [6, p. 56]

Beyond such work on typologies of use and non-use, a variety of empirical work emphasizes the role that volitionality plays. For example, Schoenebeck [71] and Baumer et al. [7] each studied situations where people took an intentionally short-term break from Twitter or from Facebook, respectively. In both studies, some individuals returned to the social media site earlier than they had intended to, pointing towards a population who use Facebook despite a professed desire to abstain.

Volitionality has also been explored with technologies aside from social media, and these studies similarly suggest that some people engage in a different manner or to a higher degree than they personally desire. Harmon and Mazmanian [42] suggest that many smartphone users find themselves in a perpetual state of tension, where they want to use their phones in a manner different than they currently do. Tran et al. [75] investigate the related phenomenon of compulsive phone use, which is usually both begun and ended by external triggers rather than by a user's willful intentions. Baumer et al. [9] also suggest sense of agency, "defined as an individual's perception that their actions are under their own control" [9, p. 2], as a central construct that can be used to organize and understand the disparate motivations that both users and non-users cite for their technology practices. Venkatesh et al. [78] also include volitionality, or "voluntariness of use," as a mediating factor in their model of technology adoption in organizational settings. A variety of other studies have suggested various ways that volitionality, i.e., an individual's belief that they have a choice about their own technology non/use, should be seen as an important focal point for research [e.g., 12, 23, 40, 80].

However, prior work has not yet engaged with the question of whether or not individuals feel that they have a choice about their own social media usage. If one simply asked individuals if they had a choice about whether or not to use social media, what would they say? This paper addresses that question, specifically focusing on Facebook, the most commonly used social media platform [62].

In this paper, we are treating volitionality as a primary and distinct phenomenon and considering non/use types, amongst other features, as predictors. Some research suggests that increasing one's sense of control is a significant motivation for departing/returning to Facebook [9] and (dis)engaging with smartphones [42]. Thus, we include non/use type as a potential predictor of volitionality to 
account for the possibility that engagement in such behaviors modifies one's perceived volitionality of Facebook use.

Although there are four distinct sense of volitionality across the two studies discussed in this paper, we chose to collapse them into a single concept. In Study 1, respondents are considered nonvolitional if they reported it was not their choice either to create an account or not create an account. Study 2 asks about continuing use, and nonvolitional respondents felt they did not have a choice to either continue using Facebook or quit (e.g. by deleting their account or deactivating) Prior research suggests that non/use practices are motivated in part by a desire for increased sense of agency, whether those practices concern adoption or continued use and whether the decision is to engage or disengage. Although Baumer et al. [9] describes continuing non/use of Facebook and Harmon and Mazmanian [42] adoption of smartphones, both studies find that users engage in use and non-use practices to, at least in part, increase their perceived volitionality. Therefore, we chose to consider volitionality as a single, distinct phenomenon.

\subsection{Imbalanced Classification}

In the survey data analyzed in this paper, the class of respondents who consider their non/use of Facebook non-volitional is significantly smaller than those who believe that they do have a choice. Many important machine learning tasks involve accounting for rare classes or events such as fraud detection [14] or disease risk analysis [47]. The challenges of working with such imbalanced datasets are well attested $[44,60]$.

There are two primary concerns when training models on datasets with imbalenced classes. First, the learning algorithm may fail to identify patterns in the rare class due to the overrepresentation of the majority class. Second, evaluation of the model may give misleading estimates of accuracy. For example, in the datasets used in this paper, only around $5 \%$ of respondents are non-volitional. A null model which predicts only volitional would achieve an accuracy of $95 \%$, a misleadingly high performance score.

To address the first concern, many potential solutions have been suggested for training models on imbalanced data. Kotsiantis et al. [50] provides a review of many such methods, including datalevel (e.g. resampling, feature selection) and algorithm-level (e.g. thresholding and cost-sensitive learning) approaches. We chose to use logistic regression due to its prevalence in the field of computational social science and ease of interpretation. Thus, we focused on resampling techniques to deal with our class imbalance problem. The simplest methods of resampling are oversampling of the minority class with replication and undersampling of the majority class to achieve a more balanced training set. However, these methods risk, respectively, overfitting to the rare classes and discarding useful data about the majority class [58]. A number of resampling techniques have been proposed which create balanced datasets by generating synthetic data drawn from the statistical neighborhoods of real datapoints in the rare class. Popular algorithms for generating synthetic data include Synthetic Minority Over-sampling Technique (SMOTE) [16] and Random Over-Sampling Examples (ROSE) [55]. We chose to use an implementation of ROSE in the R programming language for the following analyses.

To address the second concern with imbalanced classes, ROSE offers several methods for model evaluation. In this paper, we utilize a bootstrapping method in which $B$ synthetic, balanced datasets of size $N$ are fit individually by logistic regression models. Performance is determined for each bootstrapped sample by calculating area under the ROC-curve (AUC), and the distribution of AUCs are reported across all $B$ runs. AUC can provide a measure of model fit which is sensitive to the tradeoff between false- and true-positives. AUC can be interpreted as the probability that a randomly chosen pair of positive and negative training examples will be correctly classified [28]. An AUC of 0.5 represents no information (true positives are equally as likely as false positives), while

Proc. ACM Hum.-Comput. Interact., Vol. 5, No. GROUP, Article 223. Publication date: July 2021. 
1.0 represents perfect information. Although ROSE is known to overestimate accuracy [58], high AUC can provide some assurance that the features selected are indeed informative in predicting volitionality.

Although statistical methods such as ROSE can increase confidence in the findings of data-driven studies such as the present one, they are not substitutes for larger and more representative datasets. That said, these methods are important tools with which researchers can study rare phenomena, and the following studies posit volitionality as one such phenomenon which is worthy of consideration.

\section{STUDY 1: 2015 CNSS DATA}

In Study 1, we examine a relatively narrow definition of volitionality. Do survey respondents report having a choice about whether to create a Facebook account? Reporting such a choice connects with the key question of whether a respondent's Facebook non/use is intentional [9, 30, 31]. Furthermore, Study 1 only considers demographic characteristics and certain types of non/use as potential predictors of volitionality. Since demographics can predict non/use [4, 41], this study tests whether demographics can predict volitionality of non/use. It also tests whether different forms of non/use are associated with lower or higher rates of volitionality.

\subsection{Survey Materials and Data}

The data come from the 2015 Cornell National Social Survey (CNSS), which was conducted by Cornell University's Survey Research Institute ${ }^{2}$. Participants were recruited via random digit dialing, resulting in 1000 valid responses from a demographically representative sample. For this analysis, respondents who provided incomplete data were removed, leaving a total of $N=915$. The survey protocol includes a diverse array of questions posed by multiple researchers for various purposes. For this study, we utilize five questions included by the authors that address types of Facebook non/use and volitionality of account creation, as well as a number of demographic characteristics including age, gender, education level, and social and political ideology. This analysis utilizes the same dataset as Baumer [4], and the reader is directed there for a more detailed discussion of the survey protocol and a full list of demographic features.

The authors included three questions in the CNSS protocol intended to capture different types of non/use. For the purposes of this analysis, the resulting typology was considered as a predictor for volitionality of Facebook use. The questions were as follows:

- Do you currently or have you ever had a Facebook account?

- Have you ever deactivated your primary account?

- Have you ever considered deactivating your Facebook account?

The second and third questions were only shown to respondents who had answered Yes to the preceding questions. A decision tree was constructed using these three questions resulting in a four-class typology depicted in Figure 1, into which each respondent was placed. This typology was constructed based on prior literature. For example, the classes labeled never user and deactivated correspond approximately with Wyatt's [81] "resisters" and "rejecters," respectively. Considered deactivating is a behavior which Baumer et al. [5] call "lagging resistance" - a desire to leave a technology on which one does not act. Finally, current users are those who currently use Facebook and have not deactivated their accounts or considered doing so. We note that this typology considers only two types of non-use behavior, never creating an account and deactivating one's account, and does not account for other behaviors such as limiting (but not discontinuing) use or deleting one's account entirely. Furthermore, space constraints prevented us from assessing respondents' familiarity with the deactivation feature, which could provide a more nuanced view of their level

\footnotetext{
${ }^{2}$ For more details about this data set, please see https://www.sri.cornell.edu/sri/cnss.reports.cfm
} 


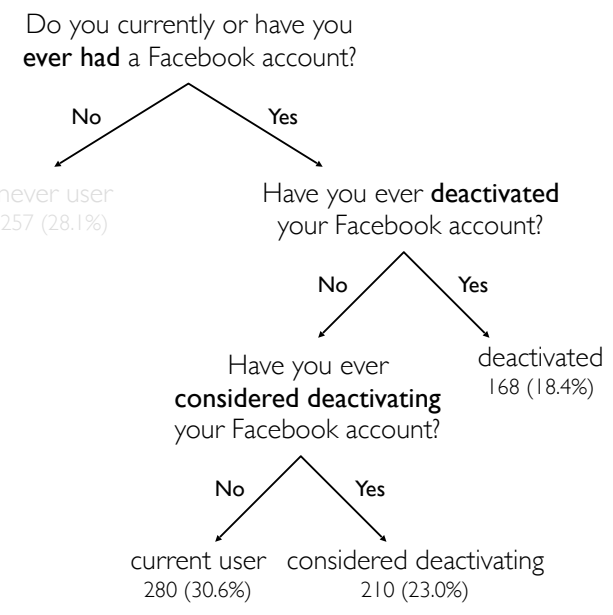

Fig. 1. Decision tree assigning the type of non/use for each respondent, including number of respondents for each type with percentages in parentheses. Respondents who do not currently have a Facebook account are greyed-out, since the analysis here focuses only on those respondents who could conceivably be called "users" since they currently have an account.

of engagement with non-use practices. The authors were limited in the number of questions to include in the CNSS and chose to focus on deactivation since it is a technical feature afforded by Facebook and a relatively common type of non-use [5]. To address these potential weaknesses, Study 2 below utilizes a more robust typology.

Volitionality was determined by respondents' answers to one of two questions included in the CNSS protocol. If a respondent indicated that they never created a Facebook account, they were asked "is not having a Facebook account a voluntary choice for you?" Alternatively, if the respondent had created an account they saw the question "Was creating a Facebook account a voluntary choice?" Volitionality, the target of the analysis, was coded as a binary variable where Yes indicated that creating or not creating an account was a voluntary choice and No represented a lack of choice. In Study 1, volitionality referred only to the point in time where a respondent chose whether or not to create an account and captured two different phenomena (voluntary use and voluntary non-use) in a single variable.

The majority of respondents fall into the category of volitional non/use (93.7\%), leaving only a small sample of non-volitional non/users (6.3\%). This class imbalance had implications for the processes of model selection and evaluation which we discuss in the following section.

There are two primary reasons that voluntary use and non-use are combined into a single "volitional" class. The first reason is practical: a multiclass model would exacerbate the existing class imbalances and make meaningful interpretation of the results difficult. The second reason is theoretical, in that volitionality is being interpreted as a single, primary phenomenon for the reasons explained in Section 2.1. 


\subsection{Analysis}

Respondents were grouped into one of two categories: Volitional (Non-)Creation and non-volitional (Non-)Creation. Our analysis sought to construct a logistic regression model using demographic features and types of non/use (Figure 1) to predict volitionality. Due to the large class imbalance and limited number of non-volitional Non/users, it was not feasible to hold out data for a testing set and the entire dataset was used to perform model selection.

Model selection was performed by iterative forward-selection of features. 18 features were considered, including the non/use types described above and demographic characteristics. To begin, we trained 18 one-predictor models and selected the model which minimized the Akaike Information Criterion (AIC). We then fixed the first predictor and tested the remaining 17 two-predictor models. This process continued, at each stage testing all $k+1$-predictor models and selecting the model with minimum AIC. We also considered for addition to the model two-way interactions of main effects which were already included: for example, the best two-predictor model used usetype and ideo, thus we tested their interaction along with the remaining 16 predictors. For this analysis, no interactions were observed to significantly improve model fit. Model selection ended whenever a likelihood-ratio test (LRT) between the $k$-and $k+1$-predictor models indicated an insignificant $(\alpha=.05)$ change in model fit.

As discussed in the introduction, both studies here utilize ROSE to balance the dataset before training by generating synthetic examples from the distribution of minority class samples (i.e. non-volitional). ROSE generates a single artificial data point by first selecting an instance $\left(\mathbf{x}_{i}\right)$ from one of the two classes $\left(Y_{0 / 1}\right)$ with equal probability. Then, it draws a new data point $(\mathbf{x})$ from a kernel density estimate centered on $\mathbf{x}_{i}$ with scale parameters $\mathbf{H}_{i}$ controlling the width of the neighborhood around $\mathbf{x}_{i}$. ROSE calculates the optimal value for $\mathbf{H}_{i}$ assuming multivariate normality of the underlying components. This process is repeated until a set of $m$ synthetic data points are generated, with roughly equal proportions of both classes.

We chose to use our real datasets, rather than the synthetic dataset generated by ROSE, to select the features to be included in our final logistic regression models. This was decided after experimentation showed that the selected features were heavily dependent on the initial random seed given to ROSE, which determines which samples are chosen to center the kernel density function. Our datasets were significantly smaller than those used in [55], which meant fewer minority class examples existed from which to generate synthetic data points. Instead, we performed model selection on the entire, real datasets and used ROSE for model evaluation to determine if the selected features had measurable impacts on volitionality.

\subsection{Results}

The final model contained three predictors: usetype (non/use type, $p<.01$ ), ideo (social ideology, $p<$ .01 ) and $e d u c$ (education level, $p<.05$ ). Odds ratios are provided in Table 1, and no multicollinearity was observed. Figure 2 depicts the same information using effects plots, which we feel is a more intuitive way of displaying the effects of the predictors on the outcome variable. Odds ratios for the full model are available in Appendix A, but the following discussion pertains to the more parsimonious reduced model.

As discussed in the introduction, class imbalances like those observed in this dataset require alternative evaluation metrics from the usual train/test accuracy paradigm. In this case, a null model which always predicted $\mathbf{1}$ (for Volitional (Non-)Creation) would achieve a very high accuracy of $93.7 \%$, but would tell us nothing about the minority class of non-volitional (Non-)Creation. We evaluated the model using ROSE's built in bootstrapping method with $B=100$. Greater numbers of runs were not observed to affect AUC, therefore 100 was chosen to limit computation time. 
Type effect plot

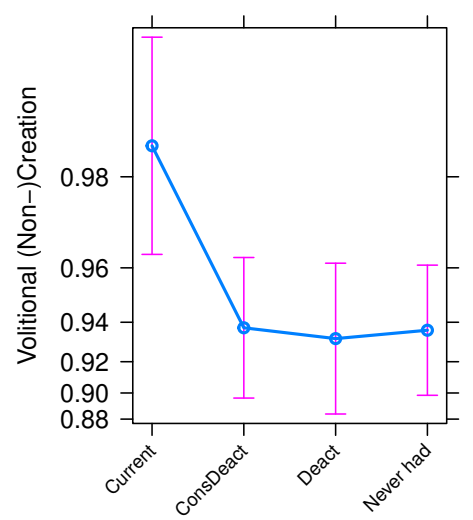

Ideology effect plot

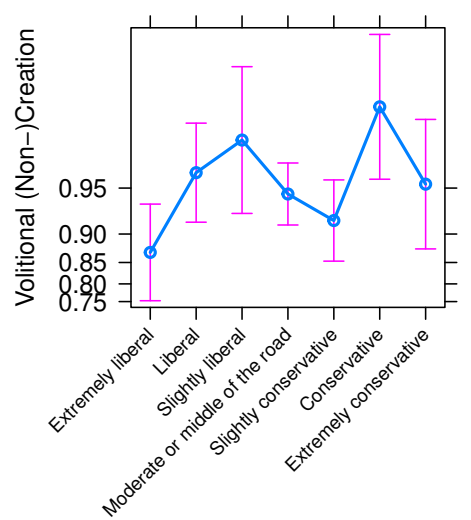

Education effect plot

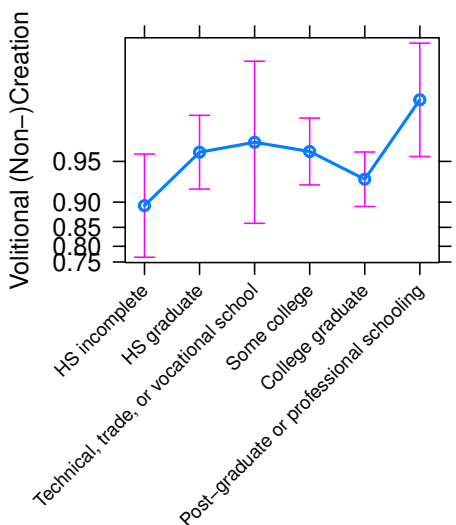

Fig. 2. Effects plots of dominant predictors for Volitional Non-/Creation, i.e., whether a respondent reported that they had a choice about whether to create (or not to create) a Facebook account. Y-axis represents marginal probability given a certain value of the predictor of a user reporting that it was their choice whether or not to create an account. X-axis represents the possible values for each predictor. All three predictors included in the final model were coded as categorical variables with no ordering.

\begin{tabular}{l||l} 
Variable & Odds Ratio \\
\hline \hline Type: ConsDeact & $0.22^{* * *}$ \\
Type: Deact & $0.22^{* * *}$ \\
Type: Never had & $0.23^{* * *}$ \\
Ideo: Extreme Lib. & $0.44^{*}$ \\
Ideo: Liberal & 1.64 \\
Ideo: Slight Lib. & 2.51 \\
Ideo: Slight Cons. & 0.62 \\
Ideo: Conservative & $4.36^{*}$ \\
Ideo: Extreme Cons. & 1.33 \\
Educ: HS Incomplete & 0.67 \\
Educ: HS Grad. & 1.69 \\
Educ: Tech, Trade, or Vocational & 2.01 \\
Educ: Some College & 1.75 \\
Educ: Post-Graduate & $3.55^{* *}$
\end{tabular}

Table 1. Odds ratios. Reference classes are as follows: Type - Current, Ideo - Moderate, Educ - College Graduate. Significance levels $p: *<.05, * *<.01, * * *<.005$

In our case, ROSE bootstrapping with $B=100$ yielded a mean and median AUC of approximately 0.75 which is generally considered a high score in fields such as applied psychology [67]. Although ROSE has been found to overestimate accuracy [58], the high AUC combined with the large effects of the selected predictors increase our confidence in the significance of these factors on volitionality of Facebook account creation. 


\subsection{Discussion}

Of the three predictors included in the final model, usetypes has the clearest interpretation: respondents who currently have a Facebook account and have not deactivated or considered deactivating report the highest levels of volitionality in their decision to create an account in the first place. The never had group who report a lack of choice resemble Wyatt [81] "excluded" users or Satchell and Dourish [70]'s "disenfranchised." Several possibilities could explain deactivated and considered deactivated users' higher probability of reporting non-volitional account creation. First, it may be that the act of deactivating one's account (or consideration thereof) leads one to feel that they did not have a choice in using Facebook in the first place. Second, the relation may be reversed: those who did not feel it was their choice to create an account may be more likely to deactivate their accounts later. Finally, there may be an unmeasured, latent variable, such as social pressures [cf. 5], that predicts both non-volitional account creation and deactivation of one's account. However, we note the similarity in effects for the three non-use types, which suggests that the significance of this factor is dominated by current users' higher propensity to report volitionality than non-users.

Education is also a significant predictor, but the relationship is not linear, i.e., higher educational attainment does not relate to higher reported volitionality. This nonlinear relationship is further supported by the observation that if education is treated as a continuous variable (ranging from "HS Incomplete" to "Post-graduate"), it is not included by model selection. Of particular note is the drop in volitionality amongst college graduates. Why might college graduates feel that they have less of a choice in their use of Facebook than those without a college degree? One possible explanation is that the careers which college graduates pursue place an emphasis on social and professional networking, making Facebook, or at least some social media platform, almost compulsory. For example, Archambault and Grudin [3] find that a majority of Microsoft employees use Facebook, and most participants agreed that online social networks were beneficial for both internal networking and external professional opportunities. Respondents who attended college recently may have also felt compelled during their studies to maintain a Facebook account in order to manage relationships with friends and colleagues, to keep abreast of events and organizations on campus, or to maintain connections from home $[5,9,72]$. As for respondents who involuntarily did not create Facebook accounts, this may be due to fears that schools and employers which scan applicants' social media accounts [27, 34, 68] could find unflattering content that would diminish their prospects [5].

Finally, social ideology also has a nonlinear relationship, and its significance in the model also disappears when treated as a continuous value. Given limited prior findings about the relationship between social ideology and (Facebook) non/use, it is difficult to find an intuitive explanation for these results. This opacity may suggest the need for a more nuanced assessment of social ideology than a simple liberal-conservative scale.

\section{STUDY 2: 2018 FACEBOOK NON/USE SURVEY}

In this study, survey respondents were asked whether their use or non-use of Facebook is voluntary. This operationalization widens the pool of non-volitional non/users to include those who continue to use the platform or engage in non-use behaviors and feel that these decisions are not entirely their own choice. In addition to demographics and non/use typology, the survey analyzed in Study 2 also includes several psychometric scales in order to determine if volitionality is related to other self-reported metrics of intentional and psychological states [8].

\subsection{Survey Materials and Data}

The data for this study comes from a survey conducted in 2018 on patterns of Facebook non/use. Recruitment was conducted via Qualtrics, whose staff recruited a representative sample of general 


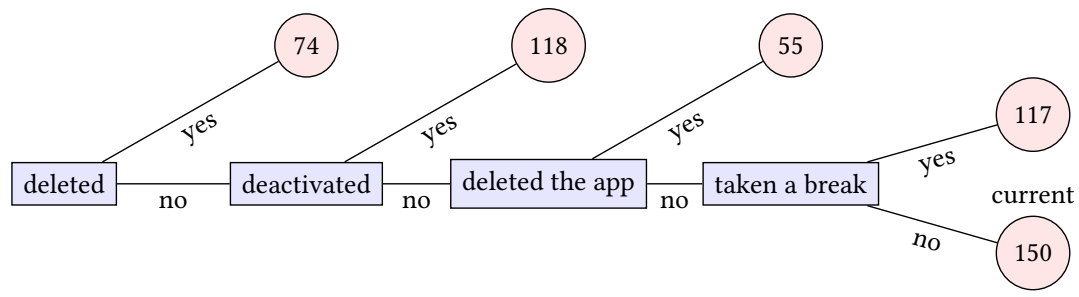

Fig. 3. Study 2 non/use typology.

internet users according to education, ethnicity, and age [63]. The researchers chose not to filter participants by gender in order to allow for the inclusion of non-binary-identifying respondents, however this resulted in the unintended side effect of a gender imbalance ( $75 \%$ female). No respondents identified as gender non-binary. 1028 potential respondents were screened out based on demographic characteristics, and the final sample used for the present analysis contained $N=514$ complete and valid responses.

The survey contained the following demographic features: education level, household income, gender, marital status, political ideology (7-point Likert from Very Liberal to Very Conservative), and age. Several psychometric scales were also included in the survey that were believed to have relevance for studying non/use. These include a 10-item version [32] of the Big 5 personality scale [19] and an 8-item inventory of Facebook use intensity [26]. From the initial 18 questions of the Bergen Facebook Addiction Scale (BFAS), 6 questions were included in this survey which loaded most highly with the 6 factors identified by Andreassen et al. [2] (Salience, Tolerance, Mood modification, Relapse, Withdrawal, and Conflict). Leiner et al. [52] identified five gratification expectations associated with Facebook usage (escape or tension-release, cognitive, social and affective gratifications, and personal integration), and the survey included a subset of 11 questions from the initial 36 which loaded highly on the identified factors. The BFAS and Leiner's uses and gratifications scales were abridged to combat survey fatigue. Finally, a 13-item sense of agency scale was included [73]. The sense of agency scale differs from Facebook volitionality, the subject of this analysis, in that it measures general perceived control over one's life, actions and environment.

The survey also contained 9 questions related to Facebook non/use. Rather than assume a typology a priori, we arrived at the classes in Figure 3 through a quantitative method described in a submission currently under review. The typology which resulted from this method contains five classes: deleted, deactivated, deletedApp, takenBreak, and current. Current users engaged in none of the nonuse behaviors, while the members of the other groups reported engaging in one or more such behaviors. The labels are assigned based on the reported non-use behavior from each respondent which would be most difficult to reverse. For example, members of the class deactivated report having deactivated their account, but have never deleted. In one sense, the class labels can be interpreted ordinally, with the most "intense" non-users represented by deleted and the least by current. However, for the purposes of the following analyses non/use type is treated as a categorical variable.

All respondents indicated that they had created an account at some point, thus there is no counterpart to the never-users in Study 1. As in Study 1, non/use type was considered as a predictor for volitionality.

Volitionality was addressed by a single statement: "It is my own choice whether or not I use Facebook." It is not limited to only the decision to create an account, as in Study 1, but also includes the senses in which continued Facebook use or non-use practices are perceived to be voluntary 
choices. As in Study 1, a significant class imbalance was observed with only $4.9 \%$ of respondents reporting that Facebook use is not a voluntary choice.

\subsection{Analysis}

Before conducting model selection, we performed factor analysis on the psychometric scales in order to extract features which were relevant to the present dataset. Factor analysis was performed on the FBI, BFAS, uses and gratifications, and sense of agency inventories since the particular characteristics of our datasets raised concerns that the factor structure might not correspond exactly to those found by the scales' authors in analyses on different datasets. The Big 5 personality scale was used in its intended manner, with one factor for each of the five personality dimensions, due to it having been validated across many different populations and cultures [11, 45, 46].

We report here the features extracted via factor analysis and provide Cronbach's alpha values of internal consistency when a factor includes more than one item. The full results of the factor analyses, including the exact items and factor loadings, can be found in Appendix 1. From the six FBI items regarding feelings towards Facebook use, we identified three factors contributing $81 \%$ of the cumulative variance: Connectedness $(\alpha=.86)$, Daily Routine $(\alpha=.93)$ and Pride. Three factors, which represent combinations of factors identified in Andreassen et al. [2], account for $73 \%$ of the variance of BFAS: Withdrawal-Conflict $(\alpha=.83)$, Salience-Tolerance-Mood $(\alpha=.84)$ and Relapse. For Leiner et al. [52]'s scale of uses and gratifications, we identify Personal Integration $(\alpha=.84)$, Social Integration $(\alpha=.91)$, Escape $(\alpha=.81)$ and Affective Gratification $(\alpha=.91)$, which account for $68 \%$ of cumulative variance. And finally, we find agreement with Tapal et al. [73] in identifying Sense of Positive Agency (SoPA, $\alpha=.79$ ) and Sense of Negative Agency (SoNA, $\alpha=.84$ ) as the relevant factors from the sense of agency scale, which contribute $43 \%$ of the cumulative variance and did not improve with additional factors. To generate predictors from these factor structures, we computed a weighted average of each item and its associated factor loading for all factors identified here, resulting in continuous predictors.

After inspection of the results, we decided to drop users whose education level was reported as "High school incomplete." Every member of this group reported that it was their choice to use Facebook, and this lack of negative-class examples resulted in uninterpretable effects plots. After dropping these respondents, the size of the dataset was $N=447$.

Once again, the goal of the analysis was to identify the factors which most significantly affected the outcome variable of volitional non/use in a binary logistic regression model. Model selection proceeded by forward AIC selection, which halted upon failure of an LRT. Analysis was conducted in the same manner as Study 1, with the most significant differences being the inclusion of psychometric scales in addition to demography and the more general sense of volitionality being addressed. Respondents were placed in one of two classes: Volitional Non/users and Non-volitional Non/users.

\subsection{Results}

The final model contained four predictors: education, Withdrawal-Conflict (BFAS), SoPA, and Agreeableness (Big 5). Odds ratios and effects plots are presented in Table 2 and Figure 4, respectively. No multicollinearity was observed among these predictors. As in Study 1, odds ratios for the full model are available in Appendix A.

Due to the severe class imbalances, we once again utilized ROSE to provide an estimate of final model accuracy. On a bootstrapped sample of 100 synthetic datasets, a mean and median AUC of 0.76 was achieved, indicating good model fit. Once again, we note the possibility of ROSE sampling overestimating accuracy, but the results increase our confidence that the included features are indeed significant for predicting volitionality of Facebook use. 
Education effect plot Withdrawal_Conflict effect plot

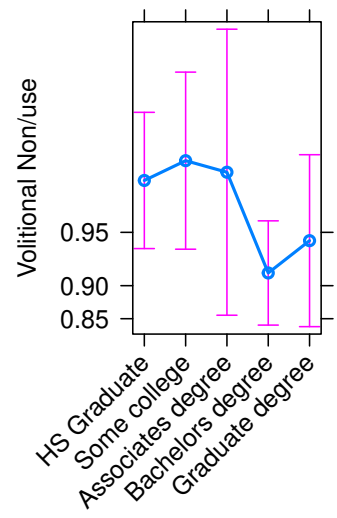

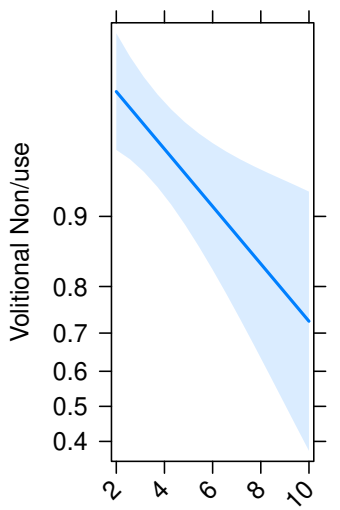

SoPA effect plot

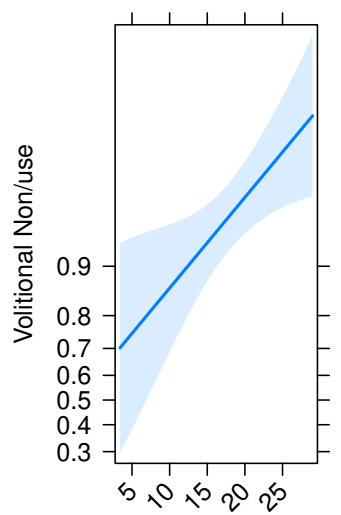

Agreeableness effect plot

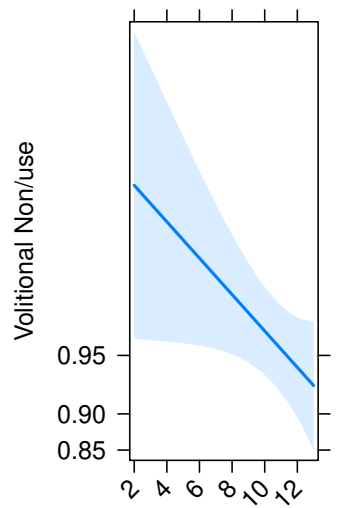

Fig. 4. Effects plots of dominant predictors for Volitional Non/use. All predictors besides education are continuous values. "SoPA" is shorthand for Sense of Positive Agency.

\begin{tabular}{l|l} 
Variable & Odds Ratio \\
\hline \hline Edu: HS Grad. & $3.66^{*}$ \\
Edu: Some College & $4.82^{*}$ \\
Edu: Associates Degree & 4.10 \\
Edu: Graduate Degree & 1.57 \\
Withdrawal_Conflict & $0.72^{* * *}$ \\
Sense of Pos. Agency & $1.16^{* *}$ \\
Agreeableness & $0.79^{*}$
\end{tabular}

Table 2. Odds ratios. Reference class for education is Bachelors degree. Significance levels $\mathrm{p}: *<.05, * *<.01$ $* * *<.005$

\subsection{Discussion}

Education once again emerges as a significant predictor of volitionality and, as in Study 1, those who have attained a bachelors degree (correspondent to "College graduate") are less likely than all others to report volitionality. This finding parallels, and reinforces our confidence in, findings about education from Study 1, where we also discuss possible interpretations of this relationship.

In contrast to Study 1's result suggesting users without a high school degree are the most likely to consider their use non-volitional, Study 2 finds this group to be unanimously volitional. Although this study lacks the qualitative data to explain this discrepancy, it perhaps highlights a shift in certain Facebook users' perception of their own agency within the system between the two studies (2015 and 2018).

Respondents who score highly on Withdrawal-Conflict report agreement with the statements "I become restless when I am unable to use Facebook," and "Facebook use has had a negative impact on my job/studies." Such experiences may lead to a situation in which individuals feel they do not have a choice whether or not to use Facebook. On the one hand, they experience discomfort and symptoms of withdrawal when away from the platform. On the other hand, continued use is tied to negative experiences in other areas of their lives. This can apply to both non-volitional users 
(remain to avoid withdrawal) and non-users (leave to avoid external problems). Baumer et al. [5] provides examples of both such instances amongst Facebook non/users. Facebook addiction, of which withdrawal and conflict are symptoms, may lead some users to feel that they do not have a choice in their use of the platform [2,15], although some have criticized the use and meaning of the BFAS scale [36]. The absence of other components of addiction, such as relapse and salience, in our model may hint that negative experiences associated with leaving and remaining on Facebook are more relevant to understanding who feels they have a choice than the broader concept of psychological or behavioral addiction [33].

Sense of Positive Agency [73] is also positively associated with reported volitionality. Those who report feeling in general that they have a high degree of sense of agency in their lives and their decisions extend that belief to their usage of Facebook. This finding is not particularly surprising, but it is valuable in that it suggests a connection between the practical, specific case of volitionality in terms of Facebook use and the psychological phenomenon of perceived sense of agency. However, the relationship may also be reversed: perceived lack of control with regard to one's Facebook use may diminish one's overall sense of agency. Furthermore, this finding reinforces our initial assertion that volitionality is related to but distinct from sense of agency; sense of positive agency is included as a significant predictor in the model, but it is not the only significant predictor.

Finally, we see a possible connection between the negative relationship with Agreeableness and care work on social media. Portwood-Stacer [66] describes how social media usage can be a form of emotional labor by which users maintain social connections. Facebook users who view their social media engagement in this way may feel a need or obligation to stay on the platform in order to keep up with family and friends, plan events, and otherwise strengthen their sense of community. This kind of empathy and a desire to help others has been associated with Agreeableness [35]. Thus, respondents who score higher on this personality trait may be more likely to use Facebook to perform emotional labor. Portwood-Stacer [66] suggests that this kind of care work is highly gendered, with women often bearing the responsibility of managing social media presence for their families. However, in the dataset analyzed here, neither agreeableness nor volitionality vary significantly according to gender or to marital status. Thus, while Baumer [4] finds that both gender and marital status predict whether an individual engages in particular forms of non/use, the results here suggest that these factors do not significantly relate with the volitionality of that non/use.

In contrast to Study 1, non/use type is not a significant predictor of volitionality in Study 2 . This discrepancy offers a number of potential insights. Non/use behavior may in fact not be predictive of volitionality, and its appearance in Study 1's model could be an artifact of the higher likelihood of nonvolitional respondents to have never had an account. Alternatively, the typologies used in the two studies, while found to be valid in other contexts, may not be the most informative ones to use when studying volitionality. If, as suggested in Section 3.4, engagement in certain non/use behaviors such as deactivation is more predictive of changes in perceived volitionality than a strict typology, then it may be more valuable to focus on these specific behaviors. Finally, there are significant differences between the two studies, including year of collection (2015 vs 2018), participant characteristics, recruitment method, typology and volitionality questions, which may explain the discrepancies.

\section{SUMMATIVE DISCUSSION}

\subsection{Interpretation of significant predictors}

Across both Study 1 and Study 2, we find several factors that significantly predict which individuals will report that they have a choice about whether or not to use Facebook. That said, volitionality was operationalized differently across the two studies. In the first study, we considered whether or 
not the act of creating a Facebook account was a voluntary choice. In the second study, volitionality was considered more generally by asking if respondents feel they have a voluntary choice about whether or not to use Facebook. This difference leaves open a variety of senses in which non/users may consider their decisions volitional or not: do they maintain accounts despite not wanting to, or do they delete or engage in other non-use practices out of a sense of need or obligation? The quantitative approach taken in this article does not allow us to disambiguate these potentially varying interpretations. However, the emergence of significant predictors gives us confidence in identifying this overarching phenomenon of volitionality, regardless of the particular behaviors considered.

Despite the different operationalizations of volitionality in each study, education emerges as a significant predictor in both datasets and has a similar interpretation: those with college degrees are less likely to consider their non/use of Facebook to be voluntary. If one considers the positive association between education level and socioeconomic status (SES), this finding may be somewhat counterintuitive. Sociological research has consistently shown that low SES is linked to lower feelings of self-efficacy and and perceived agency Blacksher [13], Wilkinson [79]. Thus, one might expect that those with higher education would be more likely to feel they have a choice in their social media use. The data analyzed here provide no evidence for this type of relationship with education, nor does SES (measured by household income) arise as a significant predictor of volitionality in either study. These findings suggests that volitionality of Facebook use, although predicted by increased sense of positive agency (Figure 4), is not entirely a manifestation of an individual's general feelings of agency in their own lives. Alternatively, volitionality may be more substantially affected by particular social and professional pressures, such as the need for networking or fear that objectionable content from one's social media may negatively impact education and work prospects. Further research should investigate this link between education and self-reported volitionality more closely.

Education is the only demographic feature (aside from social ideology, whose relationship with volitionality is rather opaque) which arises in either model. Prior work has found relationships between social media non/use and various demographic characteristics, such as age, gender, marital status, and race $[1,3,4,41]$. However, none of these appear to significantly impact perceived volitionality. Non/use type is only significant when considering volitionality of account creation in Study 1, and not in the more general sense of volitionality addressed in Study 2. To confirm that the absence of non/use type in Study 2 was not a consequence of the different typologies used, we conducted a confirmatory analysis by treating non/use as binary (current user or not, based on the effects plot in Figure 2) and did not find a significant effect. So while engagement in certain non-use behaviors may be motivated by or affect one's feelings of volitionality (at least in the case of account creation), they appear to be two separate phenomena, associated with different individual characteristics and likely driven by alternative underlying factors. These findings suggest that future work on volitionality of technology use should likely distinguish between the moment of adoption and on-going use.

\subsection{Limitations and Future Work}

In this paper, we have taken a quantitative approach to investigating the question of who feels like they do not have a choice to use Facebook. Although we found several demographic and psychometric factors to be informative in distinguishing between volitional and non-volitional non/users, the survey design does not allow us to establish causality. Additionally, the surveys did not include questions about specific reasons why users felt they did or not have a choice. Prior research has found a number of factors which influence users' volitionality regarding technology, including functional barriers to adoption or use such as accessibility or cost of a technology [81]

Proc. ACM Hum.-Comput. Interact., Vol. 5, No. GROUP, Article 223. Publication date: July 2021. 
as well as social barriers such as fear of alienation from peers or bullying [5, 61]. Although this paper suggests several factors which relate to higher or lower perceived volitionality, future work should consider the specific barriers which users face to acting completely of their own will. Future qualitative studies, especially personal interviews, would enable researchers to better understand why some individuals feel their use or non-use of Facebook is not voluntary.

The data collected in these two studies were not suitable for differentiating between different types of non-volitionality (i.e. adoption vs use and engagement vs disengagement), primarily due to significant class imbalances and limited numbers of questions in the surveys. We argue in Section 2.1 that this combination is reasonable based on prior literature, and our results show several statistical relationships between this combined volitionality concept and psychometric, demographic, and (in Study 1) non/use factors. Following the growing literature which argues for disambiguating types of non/use, e.g. [8, 61, 81], future work should also seek to explore the nuances masked by this binary distinction of volitional or non-volitional.

This study also only considered Facebook. Recent studies have found decreased popularity of Facebook amongst teenagers and young adults [57], with other platforms such as Snapchat and Instagram becoming the social media of choice for many. Individuals may also strategically manage their social media use and non-use across multiple platforms in order to engage with different communities, craft identities, and self-present to achieve their goals [23]. Whether or not users of these other technologies feel they have a choice may be dependent on separate cultural and social factors from those present on Facebook, and similar studies on volitionality may reveal important insights into the evolving patterns as social media use becomes less about individual sites and more eclectic in nature. In regard to the particular predictors which were found to be significant in this study, future work should investigate whether the same features hold importance on other social media platforms. The psychometric predictors in Figure 4 may generalize across platforms. For example, addiction-like behaviors have been observed in Instagram [49] and Twitter [48] users, and we would expect this to contribute to feelings of helplessness and non-volitionality as it does on Facebook. On the other hand, demographic predictors are likely to vary across platforms due to their different user bases and social functions. Although Facebook is currently the most popular social media platform, other platforms have unique characteristics and users which warrant study into whether they also feel like they cannot leave.

\subsection{Implications for Design and for Policy}

The results of this study suggest that there are quantifiable differences between those who consider their non/use of Facebook to be voluntary, and those who feel either compelled or excluded. Put differently, it provides results about who reports having a choice about whether or not to use Facebook, such as individuals with a bachelor's degree being more likely to report that they do not have a choice. However, further qualitative work is needed to understand why those individuals are less likely to consider their use of Facebook to be voluntary. Pending this crucial investigation, the following implications for design and policy center primarily around the existence of non-volitional non/users, with only slight discussion of the specific predictive traits identified above. In other words, how might designers and policymakers adjust their practices and understandings, given that at least some individuals' engagement with these platforms is experienced as compulsory?

5.3.1 Design. Technology designers could benefit by being aware that some users feel as though they cannot freely choose whether or not to engage with that technology. For example, reluctant users may find Facebook stressful or distracting [71] but preferable to the withdrawal-like discomfort or feelings of missing out which might accompany departing [7]. Certain design features-push notifications, infinitely scrolling timelines, and like buttons, which are designed to keep users' 
attention-may create a behavioral feedback loop which makes people feel unable to leave the platform without experiencing negative effects [10,54]. Facebook currently offers some ways to mitigate these effects, such as by limiting one's notifications ${ }^{3}$ or "unfollowing" friends to manage who appears in the News Feed ${ }^{4}$. However, these features are somewhat limited by permissive default settings and tedious manual adjustment. While a clear implication is to be mindful of addictive features and the discomfort they create for people who wish to disengage, it is unlikely that social media companies which wish to maximize engagement would willingly aid in reducing it. Furthermore, social pressures for non/use, such as work requirements or family obligations $[5,7]$, may influence volitionality just as much as, and perhaps even more than, technical design choices In other words, while design interventions could be made, designers alone should not expect to be able to overcome all the myriad forces which make users feel they do not have a choice about using Facebook or other social media.

5.3.2 Policy. Much technology policy takes a laissez faire approach to regulation which assumes that users are free to not pay for or engage with services they find objectionable. Our results, though, suggest an alternative to that narrative. Some users feel that they do not have a choice about whether or not to use Facebook. Not only do some users feel compelled to have and use an account, but also not all non-users have intentionally or knowingly opted out. Put differently, it is unlikely that these individuals are making rational, calculated tradeoff [cf. 25], such as between the benefits that social media provide and the privacy costs that they incur while using them [e.g. $17,24]$. Thus, this work suggests considering stronger regulatory protections for those who feel obligated or required to use social media. For example, laws governing Facebook's use of customer data are necessary to protect the privacy of non-volitional users who are unable to easily "optout," the most commonly prescribed solution to unacceptable practices. Our results suggest that college-educated individuals may represent one such group. Additionally, as debates take place surrounding Facebook's role in disseminating information, including polarizing and misleading types, non-volitional users are important participants in these systems and require consideration of their interests and challenges. Future work similar to that presented here can provide further insight, not only into who these populations are, but also why they feel a lack of volitionality in their technology usage, as well as how best we might go about protecting them.

\section{CONCLUSION}

This paper examines, as a primary phenomenon of interest, the volitionality of Facebook usage. Across analysis of two large surveys, we find several factors predicting an increased probability that a respondent will report their Facebook non/use as being their own choice, including currently being a Facebook user and reporting moderate (rather than extreme or centrist) political ideologies. We also find several factors predictive of decreased volitionality, including a bachelor's or higher level education and the addiction-like experiences of withdrawal and conflict. As noted above, these findings contribute an understanding of who reports that they do not have a choice about their own social media usage. While this paper offers some initial implications, further study is necessary to understanding why some populations feel a lack of volitionality about their Facebook usage, as well as how designers and policy makers might address such situations.

\footnotetext{
${ }^{3}$ https://www.facebook.com/settings?tab=notifications

${ }^{4}$ https://www.facebook.com/help/190078864497547
} 


\section{ACKNOWLEDGMENTS}

This work is supported in part by the US National Science Foundation (Grant No. IIS-1421498 and Grant No. CNS-1814533) and the Facebook Computational Social Science Methodology Research Award. Thanks to our survey participants for sharing their data and their experiences.

\section{REFERENCES}

[1] Alessandro Acquisti and Ralph Gross. 2006. Imagined Communities: Awareness, Information Sharing, and Privacy on the Facebook BT - Privacy Enhancing Technologies, George Danezis and Philippe Golle (Eds.). Springer Berlin Heidelberg, Berlin, Heidelberg, 36-58.

[2] Cecilie Schou Andreassen, Torbjørn Torsheim, Geir Scott Brunborg, and Ståle Pallesen. 2012. Development of a Facebook Addiction Scale. Psychological Reports 110, 2 (2012), 501-517. https://doi.org/10.2466/02.09.18.PR0.110.2.501-517

[3] Anne Archambault and Jonathan Grudin. 2012. A Longitudinal Study of Facebook, LinkedIn, and Twitter Use. In Proceedings of the SIGCHI Conference on Human Factors in Computing Systems (CHI '12). ACM, New York, NY, USA, 2741-2750. https://doi.org/10.1145/2207676.2208671

[4] Eric P. S. Baumer. 2018. Socioeconomic Inequalities in the Non use of Facebook. In CHI 2018. Montreal, QC, Canada, 1-14. https://doi.org/10.1145/3173574.3174190

[5] Eric P. S. Baumer, Phil Adams, Vera D. Khovanskaya, Tony C. Liao, Madeline E. Smith, Victoria Schwanda Sosik, and Kaiton Williams. 2013. Limiting, leaving, and (re)lapsing. In Proceedings of the SIGCHI Conference on Human Factors in Computing Systems - CHI '13. ACM Press, Paris, France, 3257. https://doi.org/10.1145/2470654.2466446

[6] Eric P. S. Baumer, Jenna Burrell, Morgan G. Ames, Jed R. Brubaker, and Paul Dourish. 2015. On the Importance and Implications of Studying Technology Non-Use. interactions 22, 2 (2015), 52-56. https://doi.org/10.1145/2723667

[7] Eric P. S. Baumer, Shion Guha, Emily Quan, David Mimno, and Geri K. Gay. 2015. Missing Photos, Suffering Withdrawal, or Finding Freedom? How Experiences of Social Media Non-Use Influence the Likelihood of Reversion. Social Media + Society 1, 2 (2015), 205630511561485. https://doi.org/10.1177/2056305115614851

[8] Eric P. S. Baumer, Patrick Skeba, Shion Guha, and Geri K. Gay. 2019. All Users are (Not) Created Equal: Predictors Vary for Different Forms of Facebook Non/use. Proceedings of the ACM: Human-Computer Interaction 3(CSCW) (2019).

[9] Eric P. S. Baumer, Rui Sun, and Peter Schaedler. 2018. Departing and Returning: Sense of Agency As an Organizing Concept for Understanding Social Media Non/Use Transitions. Proc. ACM Hum.-Comput. Interact. 2, CSCW (Nov. 2018), 23:1-23:19. https://doi.org/10.1145/3274292

[10] Nancy K. Baym, Kelly B. Wagman, and Christopher J. Persaud. 2020. Mindfully Scrolling: Rethinking Facebook After Time Deactivated. Social Media + Society 6, 2 (April 2020), 2056305120919105. https://doi.org/10.1177/2056305120919105

[11] V. Benet-Martinez and O. P. John. 1998. Los Cinco Grandes across cultures and ethnic groups: Multitrait multimethod analyses of the Big Five in Spanish and English. Journal of Personality and Social Psychology1 75 (1998), 729-750.

[12] Jeremy Birnholtz. 2010. Adopt, Adapt, Abandon: Understanding Why Some Young Adults Start, and Then Stop, Using Instant Messaging. Computers in Human Behavior 26, 6 (Nov. 2010), 1427-1433. https://doi.org/10.1016/j.chb.2010.04.021

[13] Erika Blacksher. 2002. On Being Poor and Feeling Poor: Low Socioeconomic Status and the Moral Self. Theoretical Medicine and Bioethics 23, 6 (2002), 455-470. https://doi.org/10.1023/A:1021381616824

[14] Richard J. Bolton and David J. Hand. 2002. Statistical fraud detection: A review. Statist. Sci. 17, 3 (2002), 235-255. https://doi.org/10.1214/ss/1042727940

[15] Anindita Chakraborty. 2016. Facebook Addiction: An Emerging Problem. American fournal of Psychiatry Residents' fournal 11, 12 (12 2016), 7-9. https://doi.org/10.1176/appi.ajp-rj.2016.111203

[16] Nitesh V. Chawla, Kevin W. Bowyer, Lawrence O. Hall, and W. Philip Kegelmeyer. 2002. SMOTE: Synthetic Minority Over-sampling Technique. fournal of Artificial Intelligence Research 16 (6 2002), 321-357. https://doi.org/10.1613/jair.953

[17] Hsuan-Ting Chen. 2018. Revisiting the Privacy Paradox on Social Media With an Extended Privacy Calculus Model: The Effect of Privacy Concerns, Privacy Self-Efficacy, and Social Capital on Privacy Management. American Behavioral Scientist 62, 10 (8 2018), 1392-1412. https://doi.org/10.1177/0002764218792691

[18] J Clement. 2020. Number of monthly active Facebook users worldwide as of 2nd quarter 2020. https://www.statista. com/statistics/264810/number-of-monthly-active-facebook-users-worldwide/

[19] Paul Costa and Robert McCrae. 2008. The revised NEO personality inventory (NEO-PI-R). The SAGE Handbook of Personality Theory and Assessment 2 (1 2008), 179-198. https://doi.org/10.4135/9781849200479.n9

[20] Jenny Davis. 2012. The Problem with Internet Addiction.

[21] Andy Dearden, Ann Light, Susan Dray, John Thomas, Mike Best, Celeste Buckhalter, Dan Greenblatt, Gaurishankar Krishnan, and Nithya Sambasivan. 2007. User Centered Design and International Development. In CHI '07 Extended Abstracts on Human Factors in Computing Systems. ACM, 2825-2828. https://doi.org/10.1145/1240866.1241087

[22] Michela Del Vicario, Alessandro Bessi, Fabiana Zollo, Fabio Petroni, Antonio Scala, Guido Caldarelli, H Eugene Stanley, and Walter Quattrociocchi. 2016. The spreading of misinformation online. Proceedings of the National Academy of 
Sciences 113, 3 (2016), 554-559.

[23] Michael A. DeVito, Ashley Marie Walker, and Jeremy Birnholtz. 2018. 'Too Gay for Facebook': Presenting LGBTQ+ Identity Throughout the Personal Social Media Ecosystem. Proc. ACM Hum.-Comput. Interact. 2, CSCW (Nov. 2018), 44:1-44:23. https://doi.org/10.1145/3274313

[24] Tobias Dienlin and Miriam J Metzger. 2016. An Extended Privacy Calculus Model for SNSs: Analyzing Self-Disclosure and Self-Withdrawal in a Representative U.S. Sample. Journal of Computer-Mediated Communication 21, 5 (8 2016), 368-383. https://doi.org/10.1111/jcc4.12163

[25] Tamara Dinev and Paul Hart. 2006. An extended privacy calculus model for e-commerce transactions. Information systems research 17,1 (2006), 61-80.

[26] Nicole B. Ellison, Charles Steinfield, and Cliff Lampe. 2007. The benefits of facebook "friends:" Social capital and college students' use of online social network sites. Journal of Computer-Mediated Communication 12, 4 (2007), 1143-1168. https://doi.org/10.1111/j.1083-6101.2007.00367.x

[27] Equal Employment Opportunity Commission and Federal Trade Commission. [n. d.]. Background Checks: What Job Applicants and Employees Should Know. https://www.eeoc.gov/eeoc/publications/background_checks_employees.cfm.

[28] Tom Fawcett. 2006. An introduction to ROC analysis. Pattern Recognition Letters 27, 8 (6 2006), 861-874. https: //doi.org/10.1016/j.patrec.2005.10.010

[29] Jesse Fox and Jennifer J. Moreland. 2015. The dark side of social networking sites: An exploration of the relational and psychological stressors associated with Facebook use and affordances. Computers in Human Behavior 45 (2015), 168-176. https://doi.org/10.1016/j.chb.2014.11.083

[30] Shaun Gallagher. 2007. The Natural Philosophy of Agency. Philosophy Compass 2, 2 (March 2007), 347-357. https: //doi.org/10.1111/j.1747-9991.2007.00067.x

[31] Shaun Gallagher. 2012. Multiple Aspects in the Sense of Agency. New Ideas in Psychology 30, 1 (April 2012), 15-31. https://doi.org/10.1016/j.newideapsych.2010.03.003

[32] Samuel D. Gosling, Peter J. Rentfrow, and William B. Swann Jr. 2003. A Very Brief Measure of the Big-Five Personality Domains. Journal of Research in Personality 37, 6 (Dec. 2003), 504-528. https://doi.org/10.1016/S0092-6566(03)00046-1

[33] Jon E. Grant, Marc N. Potenza, Aviv Weinstein, and David A. Gorelick. 2010. Introduction to Behavioral Addictions. The American fournal of Drug and Alcohol Abuse 36, 5 (Aug. 2010), 233-241. https://doi.org/10.3109/00952990.2010.491884

[34] Jeniffer Grasz. 2014. Number of Employers Passing on Applicants Due to Social Media Posts Continues to Rise, According to New CareerBuilder Survey - CareerBuilder. http://www.careerbuilder.com/share/aboutus/pressreleasesdetail.aspx?sd=6\%2F26\%2F2014\&id=pr829\&ed=12\%2F31\%2F2014

[35] William G Graziano, Meara M Habashi, Brad E Sheese, and Renée M Tobin. 2007. Agreeableness, empathy, and helping: A person $\times$ situation perspective. , 583-599 pages. https://doi.org/10.1037/0022-3514.93.4.583

[36] Mark D. Griffiths. 2012. Facebook addiction: Concerns, criticism, and Recommendations-a RESPONSE to Andreassen and colleagues. Psychological Reports 110, 2 (2012), 518-520. https://doi.org/10.2466/01.07.18.PR0.110.2.518-520

[37] Mark D. Griffiths. 2013. Social Networking Addiction: Emerging Themes and Issues. fournal of Addiction Research \& Therapy 4, 5 (2013). https://doi.org/10.4172/2155-6105.1000e118

[38] Jonathan Grudin. 1988. Why CSCW Applications Fail: Problems in the Design and Evaluationof Organizational Interfaces. In Proceedings of the ACM Conference on Computer Supported Cooperative Work (CSCW). ACM, Portland, OR, 85-93. https://doi.org/10.1145/62266.62273

[39] Jonathan Grudin and Leysia Palen. 1995. Why Groupware Succeeds: Discretion or Mandate?. In Proceedings of the European Conference on Computer-Supported Cooperative Work (ECSCW). Springer, Dordrecht, 263-278. https: //doi.org/doi.org/10.1007/978-94-011-0349-7_17

[40] Shion Guha, Eric P. S. Baumer, and Geri K. Gay. 2018. Regrets, I've Had a Few: When Regretful Experiences Do (and Don't) Compel Users to Leave Facebook. In Proceedings of the ACM Conference on Supporting Group Work (GROUP). ACM, Sanibel Island, FL, 166-177. https://doi.org/10.1145/3148330.3148338

[41] Eszter Hargittai. 2008. Whose Space? Differences Among Users and Non-Users of Social Network Sites. Fournal of Computer-Mediated Communication 13, 1 (2008), 276-297. https://doi.org/10.1111/j.1083-6101.2007.00396.x

[42] Ellie Harmon and Melissa Mazmanian. 2013. Stories of the Smartphone in Everyday Discourse: Conflict, Tension \& Instability. In Proceedings of the ACM Conference on Human Factors in Computing Systems (CHI). Paris, 1051-1060. https://doi.org/10.1145/2470654.2466134

[43] Julia M. Hormes, Brianna Kearns, and C. Alix Timko. 2014. Craving Facebook? Behavioral Addiction to Online Social Networking and Its Association with Emotion Regulation Deficits. Addiction 109, 12 (Dec. 2014), 2079-2088. https://doi.org/10.1111/add.12713

[44] N. Japkowicz and S. Stephen. 2002. The class imbalance problem: A systematic study. Intelligent data analysis 6, 5 (2002), 429-449. 
[45] O. P. John, E. M. Donahue, and R. L. Kentle. 1991. The Big Five Inventory - Versions 4a and 54. Technical Report. University of California Berkeley, Institute of Personality and Social Research, Berkeley, CA.

[46] O. P. John, L. P. Naumann, and C. J. Soto. 2008. Paradigm Shift to the Integrative Big-Five Trait Taxonomy: History, Measurement, and Conceptual Issues. In Handbook of personality: Theory and research, O. P. John, R. W. Robins, and L. A. Pervin (Eds.). Guilford Press, New York, NY, 114-158.

[47] Mohammed Khalilia, Sounak Chakraborty, and Mihail Popescu. 2011. Predicting disease risks from highly imbalanced data using random forest. BMC Medical Informatics and Decision Making 11, 1 (2011), 51. https://doi.org/10.1186/14726947-11-51

[48] Kagan Kircaburun. 2016. Effects of Gender and Personality Differences on Twitter Addiction among Turkish Undergraduates. Fournal of Education and Practice 7, 24 (2016), 33-42.

[49] Kagan Kircaburun and Mark D Griffiths. 2018. Instagram addiction and the Big Five of personality: The mediating role of self-liking. Fournal of Behavioral Addictions f Behav Addict 7, 1 (2018), 158-170. https://doi.org/10.1556/2006.7.2018.15

[50] Sotiris Kotsiantis, Dimitris Kanellopoulos, and Panayiotis Pintelas. 2006. Handling imbalanced datasets: A review. GESTS International Transactions on Computer Science and Engineering 30 (2006). https://doi.org/10.1.1.96.9248

[51] Grace Chi En Kwan and Marko M Skoric. 2013. Facebook bullying: An extension of battles in school. Computers in human behavior 29, 1 (2013), 16-25.

[52] Dominik J. Leiner, Lara Kobilke, Christina Rueß, and Hans Bernd Brosius. 2018. Functional domains of social media platforms: Structuring the uses of Facebook to better understand its gratifications. Computers in Human Behavior 83 (2018), 194-203. https://doi.org/10.1016/j.chb.2018.01.042

[53] Nicole Lindsey. 2019. FTC Facebook Investigation Could Hold Mark Zuckerberg Personally Accountable for Privacy Issues - CPO Magazine. https://www.cpomagazine.com/data-privacy/ftc-facebook-investigation-could-hold-markzuckerberg-personally-accountable-for-privacy-issues/

[54] Kai Lukoff, Cissy Yu, Julie Kientz, and Alexis Hiniker. 2018. What Makes Smartphone Use Meaningful or Meaningless? Proc. ACM Interact. Mob. Wearable Ubiquitous Technol. 2, 1 (March 2018), 22:1-22:26. https://doi.org/10.1145/3191754

[55] Nicola Lunardon, Giovanna Menardi, and Nicola Torelli. 2014. ROSE: A package for binary imbalanced learning. $R$ Journal 6, 1 (2014), 79-89.

[56] Ulrik Lyngs, Kai Lukoff, Petr Slovak, Reuben Binns, Adam Slack, Michael Inzlicht, Max Van Kleek, and Nigel Shadbolt. 2019. Self-Control in Cyberspace: Applying Dual Systems Theory to a Review of Digital Self-Control Tools. In Proceedings of the ACM Conference on Human Factors in Computing Systems (CHI). ACM, Glasgow, 131:1-131:18. https://doi.org/10.1145/3290605.3300361

[57] Marketing Charts. 2019. Facebook's Popularity Continues to Drop Among US Youth. What Are Zuckerberg's Plans? https://www.marketingcharts.com/digital/social-media-107791

[58] Giovanna Menardi and Nicola Torelli. 2014. Training and assessing classification rules with imbalanced data. Vol. 28. 92-122 pages. https://doi.org/10.1007/s10618-012-0295-5

[59] Wanda J. Orlikowski. 1992. Learning from Notes: Organizational Issues in Groupware Implementation. In Proceedings of the ACM Conference on Computer Supported Cooperative Work (CSCW). ACM, Toronto, ON, 362-369. https: //doi.org/10.1145/143457.143549

[60] Art B. Owen. 2007. Infinitely imbalanced logistic regression. Journal of Machine Learning Research 8 (2007), $761-773$.

[61] Xinru Page, Pamela Wisniewski, Bart P. Knijnenburg, and Moses Namara. 2018. Social media's have-nots: an era of social disenfranchisement. Internet Research 28, 5 (2018), 1253-1274. https://doi.org/10.1108/IntR-03-2017-0123

[62] Andrew Perrin and Monica Anderson. 2019. Share of U.S. Adults Using Social Media, Including Facebook, Is Mostly Unchanged since 2018. Technical Report. Pew Research Center, Washington, D.C.

[63] Pew Research Center. 2018. Demographics of Internet and Home Broadband Usage in the United States | Pew Research Center. https://www.pewinternet.org/fact-sheet/internet-broadband/

[64] Ethan R. Plaut. 2015. Technologies of Avoidance: The Swear Jar and the Cell Phone. First Monday 20, 11 (2015). https://doi.org/10.5210/fm.v20i11.6295

[65] Laura Portwood-Stacer. 2012. How We Talk About Media Refusal, Part 1: “Addiction”. Flow 16, 3 (2012).

[66] Laura Portwood-Stacer. 2014. Care Work and the Stakes of Social Media Refusal. http://www.newcriticals.com/carework-and-the-stakes-of-social-media-refusal/print

[67] Marnie E. Rice and Grant T. Harris. 2005. Comparing effect sizes in follow-up studies: ROC area, Cohen's d, and r. Law and Human Behavior 29, 5 (2005), 615-620. https://doi.org/10.1007/s10979-005-6832-7

[68] Diana Rodriguez. 2019. Government and Industry Are Scanning Social Media for Keywords - Make Good Choices. https://news.clearancejobs.com/2019/09/04/government-and-industry-are-scanning-social-media-forkeywords-make-good-choices/

[69] Kaleigh Rogers. 2018. Let's Talk About Mark Zuckerberg's Claim that Facebook 'Doesn't Sell Data'.

[70] Christine Satchell and Paul Dourish. 2009. Beyond the user: Use and Non-Use in HCI. In OZCHI 2009. Melbourne, Australia. https://doi.org/10.1145/1738826.1738829 
[71] Sarita Yardi Schoenebeck. 2014. Giving up Twitter for Lent: How and Why We Take Breaks from Social Media. In Proceedings of the ACM Conference on Human Factors in Computing Systems (CHI). Toronto, ON, 773-782. https: //doi.org/10.1145/2556288.2556983

[72] Madeline E. Smith, Duyen T. Nguyen, Charles Lai, Gilly Leshed, and Eric P.S. Baumer. 2012. Going to College and Staying Connected: Communication Between College Freshmen and Their Parents. In Proceedings of the ACM Conference on Computer Supported Cooperative Work (CSCW). ACM, Seattle, WA, 789-798. https://doi.org/10.1145/2145204.2145322

[73] Adam Tapal, Ela Oren, Reuven Dar, and Baruch Eitam. 2017. The sense of agency scale: A measure of consciously perceived control over one's mind, body, and the immediate environment. Frontiers in Psychology 8, SEP (2017), 1-11. https://doi.org/10.3389/fpsyg.2017.01552

[74] The Guardian. [n. d.]. Facebook under fire for 'censoring' Kashmir-related posts and accounts | Technology. https: //www.theguardian.com/technology/2016/jul/19/facebook-under-fire-censoring-kashmir-posts-accounts

[75] Jonathan A. Tran, Katie S. Yang, Katie Davis, and Alexis Hiniker. 2019. Modeling the Engagement-Disengagement Cycle of Compulsive Phone Use. In Proceedings of the ACM Conference on Human Factors in Computing Systems (CHI). ACM, Glasgow, 312:1-312:14. https://doi.org/10.1145/3290605.3300542

[76] Sherry Turkle. 2017. Alone together: Why we expect more from technology and less from each other. Hachette UK.

[77] Johan Ugander, Lars Backstrom, Cameron Marlow, and Jon Kleinberg. 2012. Structural diversity in social contagion. Proceedings of the National Academy of Sciences 109, 16 (4 2012), 5962 LP - 5966. https://doi.org/10.1073/pnas.1116502109

[78] Viswanath Venkatesh, Michael G Morris, Gordon B Davis, and Fred D Davis. 2003. User Acceptance of Information Technology: Toward a Unified View. MIS Quarterly 27, 3 (1 2003), 425-478. https://doi.org/10.2307/30036540

[79] Richard G. Wilkinson. 2002. Unhealthy Societies (1 ed.). Routledge, London, UK. https://doi.org/10.4324/9780203421680

[80] Pamela Wisniewski, Heng Xu, and Yunan Chen. 2014. Understanding User Adaptation Strategies for the Launching of Facebook Timeline. In Proceedings of the ACM Conference on Human Factors in Computing Systems (CHI). ACM, Toronto, ON, 2421-2430. https://doi.org/10.1145/2556288.2557363

[81] Sally Wyatt. 2003. Non-users also matter. The construction of users and non-users of the internet. In How users matter. The co-construction of users and technologies. MIT Press, Cambridge, MA, 67-80. https://doi.org/10.1353/tech.2006.0041

[82] Susan Wyche and Eric P. S. Baumer. 2016. Imagined Facebook: An Exploratory Study of Non-Users Perceptions of Social Media in Rural Zambia. New Media \& Society (2016). https://doi.org/10.1177/1461444815625948

[83] Susan P. Wyche, Sarita Yardi Schoenebeck, and Andrea Forte. 2013. "Facebook Is a Luxury": An Exploratory Study of Social Media Use in Rural Kenya. In Proceedings of the ACM Conference on Computer Supported Cooperative Work \& Social Computing (CSCW). San Antonio, TX, 33-43. https://doi.org/10.1145/2441776.2441783

[84] Sunkyung Yoon, Mary Kleinman, Jessica Mertz, and Michael Brannick. 2019. Is social network site usage related to depression? A meta-analysis of Facebook-depression relations. Journal of affective disorders 248 (2019), 65-72. 


\section{A FULL MODEL ODDS RATIOS}

\begin{tabular}{l|llll} 
Variable & \multicolumn{2}{|l}{ Odds Ratio } & & \\
\hline \hline age & 0.997966778 & & \\
married:divorced & 4.225602538 & Variable & Odds Ratio \\
married:separated & 0.775046245 & lelig2:catholic & 0.775547199 \\
married4:widowed & 0.694675534 & relig3:christ.orthodox & 1.199041899 \\
married5:single & 1.263965886 & relig4:jewish & 6735572.145 \\
ideo1:extr.liberal & $0.556611223^{* *}$ & relig5:muslim & 0.933657719 \\
ideo2:liberal & $1.812160746^{* *}$ & relig6:other.nonchrist & 0.46690681 \\
ideo3:slight.liberal & $2.539731848^{* *}$ & relig7:none & 0.922312241 \\
ideo5:slight.conserv. & $0.503598765^{* *}$ & hhinc1 & 1.754946427 \\
ideo6:conservative & $3.631780737^{* *}$ & hhinc2 & 0.652972212 \\
ideo7:extr.conserv & $1.221226643^{* *}$ & hhinc3 & 0.815605823 \\
party2:strong.dem & 2.39668082 & hhinc4 & 1.493065012 \\
party3:weak.dem & 1.065203991 & hhinc5 & 0.827790489 \\
party4:independent.dem & 1.156216049 & hhinc7 & 1.553370181 \\
party5:independent.mid & 1.339095411 & hhinc8 & 1.216154444 \\
party6:independent.rep & 2.146144169 & hhinc9 & 1.909688992 \\
party7:weak.rep & 1.79128809 & gender:Male & 1.598213452 \\
party8:other & 0.789231438 & usetype2:cons.deact & $0.197607273^{* * *}$ \\
educ2:some.hs & 0.908459313 & usetype3:deact & $0.184792964^{* * *}$ \\
educ3:hs.degree & 2.039092013 & usetype4:deleted & $0.229662226^{* * *}$ \\
educ4:tech.school & 1.684629898 & & \\
educ5:some.college & 1.61412049 & & \\
educ7:post.grad & 3.488546329 & &
\end{tabular}

Table 3. Odds ratios for Study 1 full model. Reference categories are as follows: married - married, ideo moderate, party - extremely Democrat, educ - college degree, relig - Protestant, hhinc - 6, usetype - current. Significance levels: ${ }^{* *}<.01,{ }^{* * *}<.001$ 


\section{B FACTOR LOADINGS}

The following tables show all questions and factor loadings used to derive the pyschometric predictors in Section 4.2.

Received August 2020; revised November 2020; accepted December 2020 


\begin{tabular}{|c|c|}
\hline Variable & Odds Ratio \\
\hline Age & 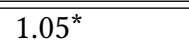 \\
\hline EduSome college, no degree & $1.56^{* *}$ \\
\hline EduAssociates degree & $1.48^{* *}$ \\
\hline EduBachelors degree & $0.13^{* *}$ \\
\hline EduGraduate degree & $0.13^{* *}$ \\
\hline FBI_Friend $11-50$ & 0.68 \\
\hline FBI_Friend51-100 & 1.47 \\
\hline FBI_Friend101-150 & 3.09 \\
\hline FBI_Friend151-200 & 2.10 \\
\hline FBI_Friend201-250 & 13.16 \\
\hline FBI_Friend251-300 & 113.94 \\
\hline FBI_Friend301-400 & 3.00 \\
\hline FBI_Friendmore than 400 & 1.63 \\
\hline FBI_Time 10 to 30 minutes & 1.97 \\
\hline FBI_Time 31 to 60 minutes & 2.12 \\
\hline FBI_Time 1 to 2 hours & 1.33 \\
\hline FBI_Time 2 to 3 hours & 71617673.78 \\
\hline FBI_Timemore than 3 hours & 4.19 \\
\hline Income & 1.12 \\
\hline GenderMale & 0.66 \\
\hline PolitViews_1Liberal & 3.03 \\
\hline PolitViews_1Slightly Liberal & 3.00 \\
\hline PolitViews_1Independent & 4.36 \\
\hline PolitViews_1Slightly Conservative & 1.84 \\
\hline PolitViews_1Conservative & 7.72 \\
\hline PolitViews_1Very Conservative & 1.43 \\
\hline AssignedTypology & 1.55 \\
\hline SoNA & 0.92 \\
\hline SoPA & $1.31^{* *}$ \\
\hline SalTolMood & 1.32 \\
\hline WithConf & $0.60^{*}$ \\
\hline Relapse & 0.99 \\
\hline FBI1 & $0.64^{*}$ \\
\hline FBI2 & 2.23 \\
\hline FBI3 & 0.56 \\
\hline Extra & 0.80 \\
\hline Agree & $0.59^{*}$ \\
\hline Conscientious & 1.22 \\
\hline Neuro & 0.99 \\
\hline Open & 1.11 \\
\hline Leiner1 & 1.03 \\
\hline Leiner2 & 0.87 \\
\hline Leiner3 & 1.20 \\
\hline Leiner4 & 0.78 \\
\hline
\end{tabular}

Table 4. Odds ratios for Study 2 full model. Reference categories are as follows: Edu - hs degree, PolitViews very liberal. See factor loading tables in the following appendix for FBI and Leiner factor names. Significance levels: ${ }^{*}<.05,{ }^{* *}<.01$ 


\begin{tabular}{lcc}
\hline Question & $\begin{array}{c}\text { Salience, Tolerance \& Mood } \\
(\alpha=.83)\end{array}$ & $\begin{array}{c}\text { Withdrawal \& Conflict } \\
(\alpha=.84)\end{array}$ \\
\hline Spent a lot of time thinking about FB use & 0.83 & \\
Felt an urge to use FB more and more & 0.85 & \\
FB use to forget about personal problems & 0.57 & 0.96 \\
Became restless if FB use prohibited & & 0.97 \\
FB use had a negative impact on job/studies & & \\
Tried to cut down FB use without success & & 0.84 \\
\hline
\end{tabular}

Table 5. BFAS: Factor analysis.

\begin{tabular}{|c|c|c|c|}
\hline Question & $\begin{array}{l}\text { Connectedness } \\
\qquad(\alpha=.86)\end{array}$ & $\begin{array}{l}\text { Daily Routine } \\
\qquad(\alpha=.93)\end{array}$ & Pride \\
\hline I feel out of touch when I haven't logged onto FB for a while & 0.64 & & \\
\hline I feel I am part of the FB community & 0.66 & & \\
\hline I would be sorry if FB shut down & 0.71 & & \\
\hline FB is part of my everyday activity & & 0.86 & \\
\hline FB has become part of my daily routine & 0.58 & 0.65 & \\
\hline I am proud to tell people I am or was on FB & & & 0.89 \\
\hline
\end{tabular}

Table 6. FBI: Factor analysis

\begin{tabular}{lcc}
\hline Question & $\begin{array}{c}\text { Sense of Negative Agency } \\
(\alpha=.84)\end{array}$ & $\begin{array}{c}\text { Sense of Positive Agency } \\
(\alpha=.79)\end{array}$ \\
\hline I am just an instrument in the hands of something else & 0.57 & \\
My actions just happen without my intention & 0.70 & \\
Consequences of my actions don't logically follow my actions & 0.71 & \\
My movements are automatic - my body simply makes them & 0.64 & \\
The outcomes of my actions generally surprise me & 0.75 & \\
Nothing I do is actually voluntary & 0.50 & 0.60 \\
I feel like I am a remote-controlled robot & 0.68 & 0.74 \\
I am in full control of what I do & & 0.55 \\
I am the author of my actions & & 0.63 \\
Things I do are subject only to my free will & & 0.55 \\
The decision whether and when to act is within my hands & & 0.67 \\
My behavior is planned by me from the beginning to the end & & \\
I am responsible for everything that results from my actions & & \\
\hline
\end{tabular}

Table 7. Sense of Agency: Factor analysis 


\begin{tabular}{|c|c|c|c|c|}
\hline Question & $\begin{array}{l}\text { Personal in- } \\
\text { tegration } \\
(\alpha=.84)\end{array}$ & $\begin{array}{l}\text { Social inte- } \\
\text { gration } \\
(\alpha=.91)\end{array}$ & $\begin{array}{l}\text { Escape } \\
(\alpha=.81)\end{array}$ & $\begin{array}{l}\text { Affective Gratifi- } \\
\text { cation } \\
(\alpha=.91)\end{array}$ \\
\hline I use FB because it makes me ease off & 0.50 & & & \\
\hline I use FB to inform myself about certain topics & 0.57 & & & \\
\hline I use FB to receive advice and recommendations & 0.61 & & & \\
\hline I use FB to express who I am & 0.72 & & & \\
\hline I use FB to share my views and opinions & 0.73 & & & \\
\hline I use FB to keep in touch with friends & & 0.89 & & \\
\hline I use FB to exchange with my friends and family & & 0.70 & & \\
\hline I use FB because I am bored & & & 0.68 & \\
\hline I use FB to occupy myself & & & 0.81 & \\
\hline I use FB because it is fun & & & & 0.61 \\
\hline I use FB because it is entertaining & & & & 0.84 \\
\hline
\end{tabular}

Table 8. Leiner's uses and gratifications: Factor analysis 